\title{
INTEGRATED PERFORMANCE ASSESSMENT; STUDENT'S PERCEPTION AND ITS RELEVANCE TO CLINICAL PRACTICE AS COMPARED WITH TRADITIONAL OSPES.
}

1. FCPS

Associate Professor Physiology, Member of Department of Health Professions Education, Al-Nafees Medical College, Isra University, Islamabad.

2. FCPS, MHPE,

Professor of Anatomy \& Member of Department of Health Professions Education, Al-Nafees Medical

College, Isra University, Islamabad.

3. FCPS,

Assistant Professor Radiology, Team member of Year 01 Modules Al-Nafees Medical College, Isra University, Islamabad.

4. M.Sc (Statistician)

Correspondence Address:

Dr. Munazza Asad

Associate Professor Physiology

Al Nafees Medical College \& Hospital

Isra University, Islamabad.

munazza_wah@yahoo.com

Article received on:

14/02/2017

Accepted for publication:

25/05/2017

Received after proof reading:

03/07/2017

\section{Munazza Asad', Khadija Iqbal', Aisha Asim ${ }^{3}$, Sabir Farman $^{4}$}

ABSTRACT... Objectives: To assess first year MBBS students' perceptions regarding Integrated Performance Assessment and its relevance to clinical practice as compared with traditional OSPEs. Study Design: Cross-sectional observational study. Setting: Al Nafees Medical College, Isra University, Islamabad. Period: Final week of First year MBBS students' professional exam held in November 2013. Methodology: Both interactive and static stations were developed according to predetermined assessment blueprint. Clinical scenarios were used as triggers followed by tasks relating to laboratory skills and or relevant physical examination on standardized subjects. Two to three tasks were given at each station. Checklists for standardized marking of observed stations were also developed. Feedback questionnaire was given to find out overall perception of students regarding this assessment process at the end of examination. The questionnaire comprised of 18 statements to be rated on 5-point Likert scale. Results: Almost all the students agreed that Integrated Performance Assessment was better than traditional OSPEs. $73 \%$ of students agreed that stations were well organized and $83.4 \%$ showed that the time duration for task completion was appropriate. $75 \%$ agreed that stations reflected integration of various disciplines. $64 \%$ were of the opinion that basic science knowledge was linked to clinical practice. $72.1 \%$ were of the opinion that it involved critical thinking in clinical context. However, students suggested improving further in organization and integration of stations. Conclusion: Students perceived IPA as a better tool of assessing application of basic science concepts and its clinical relevance in integrated curriculum format.

Key words: Integrated Performance Assessment, OSPE, laboratory skills.

Article Citation: Asad M, Iqbal K, Asim A, Farman S. Integrated performance assessment; student's perception regarding and its relevance to clinical practice as compared with traditional OSPES. Professional Med J 2017;24(7):972-976. DOI: $10.17957 / T P M J / 17.3980$

\section{INTRODUCTION}

The medical curriculum is changing throughout the world. ${ }^{1}$ The clinical content is being linked with the basic sciences content. Beane first used the term integrated curriculum and now it is gaining popularity. ${ }^{2}$ Now the transdisciplinary MacMaster approach is also widely used. The knowledge is now accompanied with skills and attitude. The first two years of M.B.B.S are now used as triggers to develop clinical skills in students. ${ }^{3}$ The practical in traditional curriculum are now being replaced with skill labs. The skills are now making a relatively important component of practical exams. ${ }^{4}$ The initial version of skills was applied in Objective structured exam. The static stations were replaced with some task given to the students and marking was done with the help of a key. ${ }^{5}$ The use of OSPE was also beneficial as some objectivity was incorporated but then the question arose that integration is done in theory but in practical integration was missing. ${ }^{6}$ The new concept of integration in basic sciences and clinical sciences is integrated practical assessment. IPA is gaining popularity amongst the medical students and they feel it a logical way to assess the performance of the students. ${ }^{7}$ Some basic sciences subjects like Anatomy are blamed for spotter exam in the name of OSPE. The educationists think that the higher levels of taxonomy cannot be judged through these spotting exams. ${ }^{8}$

The level of assessment as well as the level of cognition increases as we integrate the disciplines. The idea of integrating the disciplines in practical exam opens the first door towards patient 
centered teaching. ${ }^{9}$ The cognition level of exam increases which raises the reliability and validity of exams. Initially there was trend of spotting in basic sciences with replacement with the method of steeplechase method mentioning the action or function of particular structure or instrument. ${ }^{10}$ The scientists which favor this method believe that the recognition of human specimen is also necessary for the students learning. But integration or level of cognition remains low with these methods. The oral exams were added to supplement the deficiency of knowledge in the students but conduction of oral exams for a large number of students was difficult. The element of bias was also a factor which went against the oral exams. Structured oral exams were conducted but the logistics were still a problem for the faculty. ${ }^{10}$ Integrated practical assessment is involvement of many disciplines including the basic sciences and clinical sciences.

Criterion referenced Modified Ebel's method is used preferably for calculating the cut point scores for passing or failing the students. ${ }^{11}$ Some researchers prefer the Angoffs method for this purpose. The response of students in the beginning was not so encouraging but now it is gaining popularity worldwide. The integrated nature of practical exam is now accepted and the students also study in an integrate manner. ${ }^{6}$ The content to be sampled includes histology slides, radiographs, pathology slides, gross anatomy specimen and physiology apparatus to determine functions and some biochemical tests to access the nature of disturbances in metabolism. ${ }^{8}$ The students also love the idea of incorporation of ethics and communication skills in IPAs. In Pakistan some medical schools have adopted the IPAs for assessing the students' performance. Al Nafees medical college is one of the schools progressing to the spiral integrated curriculum. This study was conducted to assess first year MBBS students' perceptions regarding Integrated Performance Assessment and its relevance to clinical practice as compared with traditional OSPEs.

\section{METHODOLOGY}

It was a Cross-sectional observational study conducted at Al Nafees Medical College, Isra University, Islamabad, during the final week of First year MBBS students' professional exam held in November 2013. Research was conducted accordingly to the principles of the declaration should be included.

Spirally integrated modules were developed for basic sciences. First spiral aimed at systembased modules comprising anatomy, Physiology, biochemistry, Ethics and professionalism was also incorporated in the modules. Multidisciplinary team was formulated for developing competencybased Integrated Performance Assessment (IPA), for First year medical students. This assessment tool serves for testing multiple competencies related to knowledge, skills and attitude. Faculty members from both basic as well as clinical sciences facilitated the skill-related sessions. Level of achievement of competencies was defined according to the years of undergraduate education. Practical performance and clinical skills like history taking, physical examination, and counseling skills were assessed in a clinical context. Relevant ethical and professional aspects were also addressed. Content validity was ensured by developing IPA construction template and discussion during planning meetings. Both interactive and static stations were developed according to predetermined assessment blueprint. Ninety eight M.B.B.S students were included in the study. Clinical scenarios, models, videos, X-rays were used as triggers followed by tasks relating to laboratory skills and or relevant physical examination on standardized subjects. Two to three tasks were given at each station. Equal time was given on each station. On interactive stations faculty member as an observer was present. Checklist \& rating scale for standardized marking of observed stations were also developed. Students were rated on all competencies incorporated in an IPA on three category scale of superior, adequate \& needs improvement. Global rating scale was used to rate the students.

Feedback questionnaire was given to find out overall perception of students regarding this assessment process at the end of examination. 
The questionnaire comprised of 18 statements to be rated on 5-point Likert scale. The participants were explained the purpose and method of this research project. An informed consent was obtained from them to join this research project. The participation in this study was voluntary and they could withdraw from study any time without giving any reason to do so. They were informed that confidentiality was guaranteed and data would be strictly kept anonymous. They were given the liberty of seeking any clarification.

\section{EXAMPLE OF AN IPA}

A 60 year old, chronic smoker came to the OPD with the complaint of on-and-off episodes of coughing and breathlessness for the last 3 years. Task 1

Perform peak expiratory flow rate on the patient (standardized patient)

Task 2

Identify the impressions marked on specimen (lung specimen)

Task 3

Identify the marked structures on the chest radiograph (X-ray chest)

Task 4

Interpret the data (arterial blood gases report)

\section{RESULTS}

Almost all the students agreed that Integrated Performance Assessment was better than traditional OSPEs. Of the students, $73 \%$ agreed with the organization and content of the tasks for various stations. Most of them (83.4\%) showed that the time duration for task completion was appropriate. $75 \%$ agreed that stations reflected integration of various disciplines. $67 \%$ were of the opinion that instructional strategies matches with the assessments and $64 \%$ were of the opinion that basic science knowledge was linked to clinical practice. $72.1 \%$ were of the opinion that it involved critical thinking in clinical context. Degree of psychological stress elicited by IPA was less and wide knowledge area was covered. (Figure-1). Figure-2 \& 3 shows that IPA helped in creating connections across various disciplines. Instructions and cases were appropriate. Tasks reflected learning objectives as discussed in the modules.
Feedback Related to integration of Discipline \& Teaching Strategies

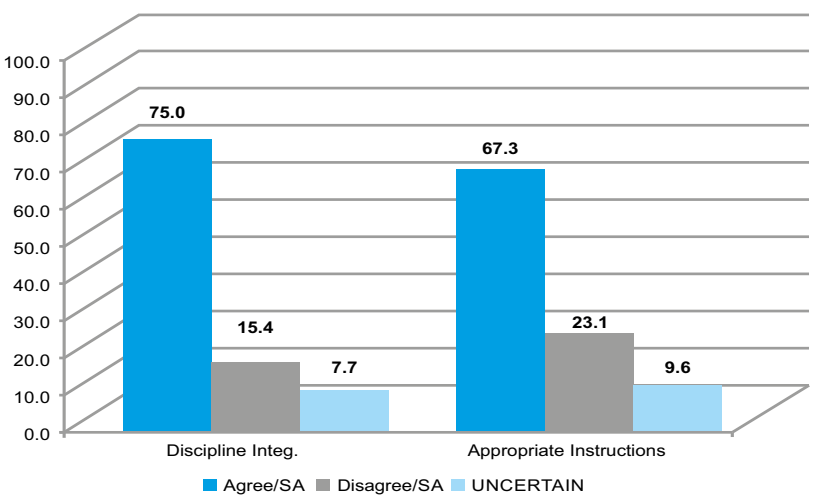

Figure-1. Students response regarding IPA effectiveness.

Students response regarding IPA effectiveness

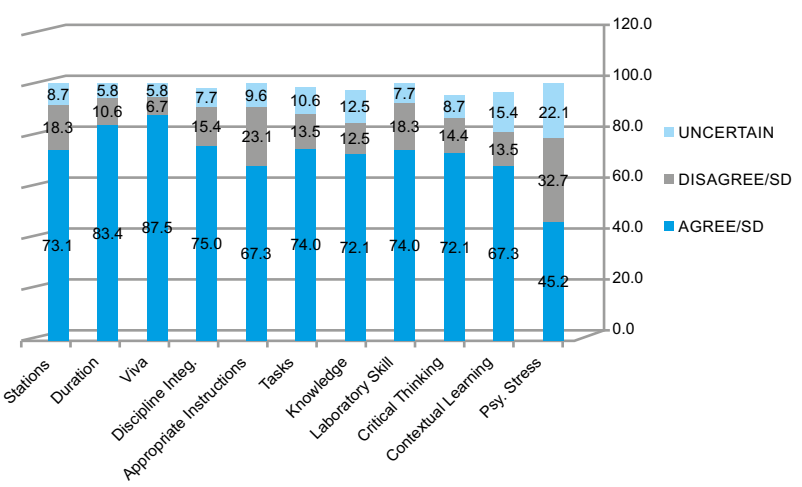

Figure-2. Feedback related to integration of discipline \& teaching strategies.

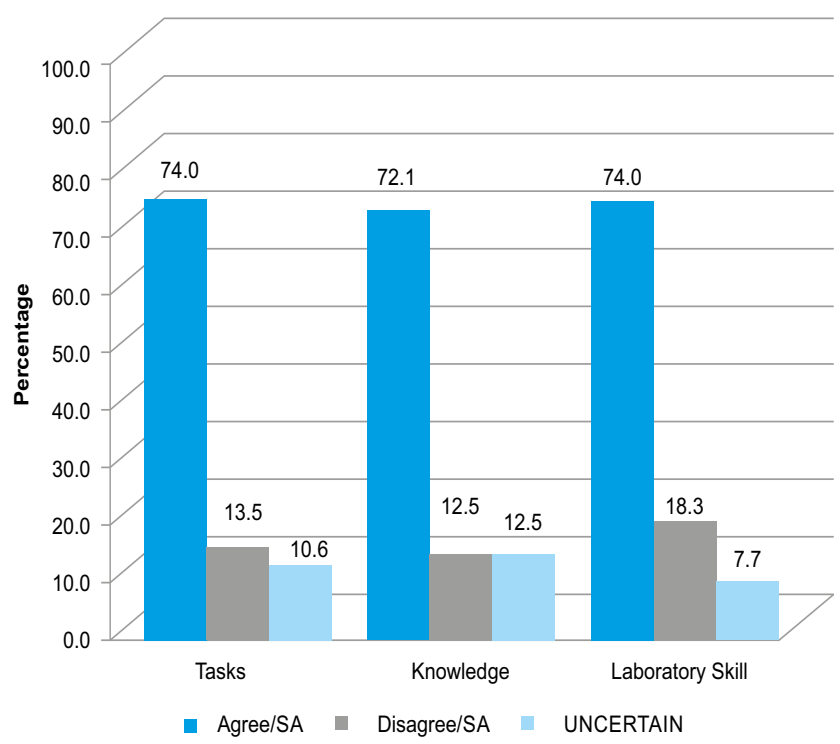

Figure-3 


\section{DISCUSSION}

The assessment methodology has changed over the past few years. ${ }^{12}$ Focus is now on the knowledge as well as the skill component. Attitude is given a presentable weightage so as to incorporate ethics in the future doctors. ${ }^{13}$ The components of assessment are now blue printed in order to give justifiable results. The term student centered teaching is now taking the actual form. ${ }^{14}$ The students enjoy when they are taught in contextual manner. The present study showed that the students are adapting to the integrated system of practical examination. Th IPA construction is a skilled based task. ${ }^{15}$ Faculty training is a must for this tasks. $73 \%$ of students agreed that stations were well organized. Some other studies have shown that the content selection for IPA is the key element in its success. IPA is basically constructed with an aim to evaluate the competency of the leaner in relation with the integration of basic and clinical knowledge. ${ }^{16}$ Variation in students' performance from station to station resolve measurement errors if the stations are developed according to the blue print. All the content is mapped properly and competencies are identified according to the level of the class. ${ }^{17}$ Reliability also depends upon the test length. Many researchers have shown that at least 6 hrs duration of IPA is reliable. ${ }^{18}$ The number of stations must be more than ten. But sometimes the time given for a particular task is not sufficient which leads to anxiety among the students but in our study $83.4 \%$ showed that the time duration for task completion was appropriate.

$75 \%$ agreed that stations reflected integration of various disciplines. $64 \%$ were of the opinion that basic science knowledge was linked to clinical practice. $72.1 \%$ were of the opinion that it involved critical thinking in clinical context. When medical schools switch to the integrated curriculum the response of students matters a lot. In a study students have mentioned that learning normal histology and then integrating it with abnormalities in pathology is a great experience..$^{19}$ It helps students to relate the disease with the cause which is the essence of learning. In china and in UK the practical sessions are also on an integrated format. ${ }^{20}$ The stress is a major problem when a student has to relate different disciplines. Sometimes the time is short and preparation of IPA is difficult for the students but the pleasure which a student gains at the completion of an integrated task is a life time experience. ${ }^{21}$ This is what they have to do as doctors on real patients. Considering the importance of lifelong learning and evidence-based medicine, many medical schools around the world teach students to evaluate the integrated courses and participating students gave positive feedback about the course. ${ }^{22}$ This shows that integrated assessment is the need of hour and we should incorporate this in our curriculum.

\section{CONCLUSION}

Students perceived IPA as a better tool of assessing application of basic science concepts and its clinical relevance in integrated curriculum and it addresses multiple competencies that are required by a good physician.

Copyright@ 25 May, 2017.

\section{REFERENCES}

1. Rao RH. Prospective in medical education. A Blueprint for reforms of medical education in japan. Keio J Med 2006; 55:81-95.

2. Harden RM. The integration ladder: a trial for curricular planning\& education. Med Educ 2000; 34:351-7.

3. Parsell GJ, Bligh J. The charging context of undergrad medical education. Postgrad Med J 1995; 71:397-403.

4. Vishwakarma K, Sharma M, Matreja PS, Giri VP What is an objective structured practical examination in anatomy? Anat Sci Educ. 2013; 3:23-34.

5. Jaswal S, Chattwal J, Kaur J, Gupta S, Singh T Assessment for learning with Objectively Structured Practical Examination in Biochemistry. Int $\mathrm{J}$ Appl Basic Med Res. 2015; 5(1):71-5.

6. Abraham RR, Raghavendra R, Surekha K, Asha K. A trial of the objective structured practical examination in physiology at Melaka Manipal Medical College, India. Adv Physiol Educ. 2009; 33(1):21-3.

7. Malhotra SD, Shah KN, Patel VJ. Objective structured practical examination as a tool for the formative assessment of practical skills of undergraduate students in pharmacology. J Educ Health Promot. 
2013 Sep 30; 2:53-5.

8. Abraham RR, Raghavendra R, Surekha K, Asha K. A trial of the objective structured practical examination in physiology at Melaka Manipal Medical College, India.

9. Lakshmipathy K. MBBS student perceptions about physiology subject teaching and objective structured practical examination based formative assessment for improving competencies. Adv Physiol Educ. 2015 Sep; 39(3):198-204.

10. Kamath MG, Pallath V, Ramnarayan K, Kamath A, Torke S, Gonsalves J. Standard setting of objective structured practical examination by modified Angoff method: A pilot study.Natl Med J India. 2016 MayJun; 29(3):160-162.

11. Menezes RG, Nayak VC, Binu VS, Kanchan T. Objective structured practical examination (OSPE) in Forensic Medicine: students' point of view. J Forensic Leg Med. 2011 Nov; 18(8):347-9.

12. Azer SA, Hasanato R, Al-Nassar S, Somily A. MM Introducing integrated laboratory classes in a PBL curriculum: impact on student's learning and satisfaction. BMC Med Educ. 2013 May 24; 13:71.

13. Malik SL, Manchanda SK, Deepak KK, Sunderam KR. The attitudes of medical students to the objective structured practical examination. Med Educ. 1988 Jan; 22(1):40-6.

14. Burgess A, Mellis C. Feedback and assessment for clinical placements: achieving the right balance. Adv Med Educ Pract. 2015 May 19; 6:373-81.

15. Wijerathne B, Rathnayake G. Medical students' attitudes and perspectives regarding novel computer-based practical spot tests compared to traditional practical spot tests. Can. Med Educ J. 2013 Sep 30; 4(2):e41-8.

16. Mainthia R, Tarpley MJ, Davidson M, Tarpley JL. Achievement in surgical residency: are objective measures of performance associated with awards received in final years of training? J Surg Educ. 2014 Mar-Apr; 71(2):176-81.

17. Thompson AR, Braun MW, O'Loughlin VD. A comparison of student performance on disciplinespecific versus integrated exams in a medical school course. Adv Physiol Educ. 2013; 37:370-376.

18. Huang L, Cheng L, Cai Q, Kosik RO, Huang Y, Zhao X, Xu GT, Su TP, Chiu AW, Fan AP. Curriculum reform at Chinese medical schools: what have we learned? Med Teach. 2014; 36:1043-1050.

19. Wilkerson L, Wimmers P, Doyle LH, Uijtdehaage S. Two perspectives on the effects of a curriculum change: student experience and the United States medical licensing examination, step 1. Acad Med. 2007; 82(10 Suppl):21-3.

20. Inam SB. Experience of teaching critical appraisal of scientific literature to undergraduate and postgraduate students at the Ziauddin Medical University, Karachi, Pakistan. Int J Health Sci (Qassim) 2007; 1:119-124. [PMC free article] [PubMed].

21. Beveridge AA. Encouraging general practitioners to train medical students. Med J Aust. 2008; 189:236. [PubMed].

22. Rauf A, Shamim MS, Aly SM, Chundrigar T, Alam SN. Formative assessment in undergraduate medical education: concept, implementation and hurdles. J Pak Med Assoc. 2014; 64:72-75.

\begin{tabular}{|c|c|c|c|}
\hline \multicolumn{4}{|c|}{ AUTHORSHIP AND CONTRIBUTION DECLARATION } \\
\hline Sr. \# & Author-s Full Name & Contribution to the paper & Author $=$ s Signature \\
\hline 1 & Dr. Munazza Asad & $\begin{array}{l}\text { Principal investigator of the } \\
\text { project: manuscript writing } \\
\text { and data collection }\end{array}$ & \\
\hline 2 & Dr. Khadija Iqbal & $\begin{array}{l}\text { Substantial contributions to } \\
\text { conception and designing } \\
\text { the work and drafting the }\end{array}$ & \\
\hline 3 & Dr. Aisha Asim & $\begin{array}{l}\text { article } \\
\text { Revising it critically for } \\
\text { important intellectual innut }\end{array}$ & stas \\
\hline 4 & & $\begin{array}{l}\text { Substantial contribution } \\
\text { in data analysis and } \\
\text { interpretation }\end{array}$ & 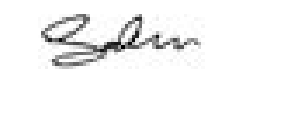 \\
\hline
\end{tabular}

